\title{
Qualidade da água no Médio Paraopeba e seus impactos socioambientais após rompimento da Barragem da Mina do Córrego do Feijão, Brumadinho, Minas Gerais, Brasil
}

\section{Lucas Alves Barros dos Santos*, Nicole Silva Gomes, Karolina Santos Hugo, Márcia Sabrina Lopes Amaral e Hygor Aristides Victor Rossoni}

Universidade Federal de Viçosa. Instituto de Ciências Exatas e Tecnológicas. Curso de Tecnologia em Gestão Ambiental. Campus Florestal. Rodovia LMG 818, km 6. Florestal-MG, Brasil (CEP 35690-000).*E-mail: lucas.santos3@ufv.br.

Resumo. O rompimento da barragem no complexo da Mina Córrego do Feijão da Mineradora Vale S.A., em Brumadinho, Minas Gerais, ocorrido em 25 de janeiro de 2019, acarretou uma série de impactos socioambientais. Após o rompimento, foram depositados na Bacia do Rio Paraopeba cerca de 12 milhões de metros cúbicos de rejeitos minerários. Sendo assim, este estudo objetiva discutir os impactos surgidos com a deterioração da qualidade da água desta bacia nos trechos do rio que percorrem cinco municípios localizados no Médio Paraopeba. Neste contexto, o índice de qualidade da água (IQA), as concentrações de metais pesados ( $\mathrm{Fe}, \mathrm{Cu}, \mathrm{Mn}$ e $\mathrm{Cr}$ ), oxigênio dissolvido e turbidez, foram utilizados para a análise da qualidade da água. Com isso, foi observado que, ao longo dos trechos do rio, o IQA e as concentrações de $\mathrm{Fe}, \mathrm{Cu}, \mathrm{Mn}$ e $\mathrm{Cr}$ encontram-se fora dos limites exigidos pela legislação. Estas condições da qualidade da água acarretam em limitações para usos múltiplos, no entanto não se atribui apenas ao rompimento da barragem, uma vez que o rio apresentava historicamente altas concentrações de contaminantes. Por fim, constata-se que este evento corroborou para a deterioração da água, e por isso, devem ser projetadas soluções que afastem os riscos de desabastecimento dos municípios.

Palavras-chave: Dano ambiental; Gestão de recursos naturais; Políticas socioambientais.

Abstract. Water quality in the Middle Paraopeba and its social and environmental impacts after the rupture of the Dam of the Vale Stream Mine, Brumadinho, Minas Gerais, Brazil. The rupture of the dam in the Córrego do Feijão mine complex of the mining company Vale S.A., in Brumadinho, Minas Gerais, which occurred on January 25, 2019, resulted in a series of socioenvironmental impacts. After the dam burst, about 12 million
Recebido

$23 / 12 / 2020$

Aceito

$10 / 04 / 2021$

Disponível on line

$12 / 04 / 2021$

Publicado

$30 / 04 / 2021$

Acesso aberto

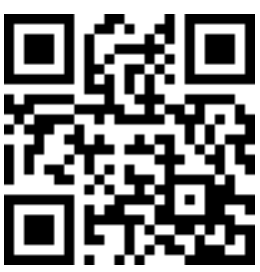

(1) 0000-0002-8256-3434 Lucas Alves Barros dos Santos

D 0000-0002-1200-627X Nicole Silva Gomes

0000-0001-6270-8061 Karolina Santos Hugo

ISSN 2359-1412/RBGAS-2020-0183/2021/8/18/18/291

Rev. Bras. Gest. Amb. Sustent.

http://revista.ecogestaobrasil.net 
cubic meters of mining waste were deposited in the Paraopeba River Basin. Thus, this study aims to discuss the impacts raised by the deterioration of water quality in this basin stretches of the river that run through five counties located in the Middle Paraopeba. In this context, the water quality index (IQA), the concentrations of heavy metals ( $\mathrm{Fe}, \mathrm{Cu}, \mathrm{Mn}$ and $\mathrm{Cr}$ ), dissolved oxygen and turbidity were used for the analysis of water quality. With that, it was observed that, along the stretches of the river, the IQA and the concentrations of $\mathrm{Fe}, \mathrm{Cu}, \mathrm{Mn}$ and $\mathrm{Cr}$ are above what is required by the legislation. These conditions of water quality result in limitations for multiple uses, however it is not attributed only to the rupture of the dam, since the river has historically had high concentrations of contaminants. Finally, it appears that this event corroborated the deterioration of the water, and therefore, solutions must be devised to remove the risk of shortages in the municipalities.

Keywords: Environmental damage; Natural resource management; Socio-environmental policies.
(D) 0000-0002-0241-7059

Márcia Sabrina Lopes

Amaral

(1) 0000-0002-6088-6144 Hygor Aristides Victor Rossoni

\section{Introdução}

0 rompimento da barragem no complexo da Mina Córrego do Feijão, de propriedade da Mineradora Vale S.A., em Brumadinho, Minas Gerais, ocorrido em 25 de janeiro de 2019, depositou no Vale do Ribeirão Ferro Carvão, que é afluente do Rio Paraopeba pela margem direita, cerca de 12 milhões de metros cúbicos de rejeitos minerários. A massa de rejeitos antes depositada na barragem, varreu o que estava em seu caminho até desaguar no Rio Paraopeba, arrastando pessoas, animais, materiais diversos, vegetação, histórias e direitos.

Situada na região sudeste do Estado d Minas Gerais, a Bacia Hidrográfica do Rio Paraopeba possui área de $12.054 \mathrm{~km}^{2}$ e divide-se nas Regiões do Alto, Médio e Baixo Paraopeba. 0 curso principal é o Rio Paraopeba (afluente da margem esquerda do Rio São Francisco), que nasce no Município de Cristiano Otoni, e percorre aproximadamente 550 $\mathrm{km}$ até a sua foz, na Represa de Três Marias, no Município de Felixlândia. É sabido que o rio tem importantes afluentes e sistemas de armazenamento de água para municípios da Região Metropolitana de Belo Horizonte, a terceira maior do país, o que trouxe uma ampla insegurança em relação aos recursos naturais devido à possibilidade de contaminação do ar, do solo e das águas da Bacia do Rio Paraopeba.

O Rio Paraopeba é um dos formadores do reservatório da Usina de Três Marias, de Salto do Paraopeba e Retiro Baixo, e da barragem de nível da Usina Termelétrica de Igarapé. De forma que, os principais usos da água são para a geração de energia elétrica, abastecimento público e industrial, com destaque para mineração. Tem importantes afluentes pela margem direita, como os Rios Maranhão e Betim e o Ribeirão São João, e pela margem esquerda, os Rios Camapuã, Manso e Pardo e o Ribeirão Serra Azul (CPRM, 2019).

Pelo caráter ecossistêmico do rompimento da barragem no Complexo da Mina Córrego do Feijão, são percebidos impactos ambientais relacionados à inutilização e estigmatização de significativas áreas produtivas e não produtivas, a impossibilidade do exercício das atividades econômicas e de lazer ligadas ao Rio Paraopeba, e ainda as práticas de subsistência e de perpetuação dos modos de vida, conforme descrito por Felippe (2020) no relatório da expedição geográfica no Vale do Rio Paraopeba. Nesse 
contexto, o rio é um corpo social que conecta áreas e produz territorialidades específicas; é fonte de sustento econômico de famílias e cadeias produtivas, como também é o local da construção da convivência social de grupos de tradição ribeirinha, pesqueira, indígenas e quilombolas; é onde manifestações culturais e religiosas são fundadas e perpetuadas, onde memórias e identidades de comunidades inteiras são projetadas.

Queiroz e Oliveira (2018) apontam as dificuldades encontradas pelas comunidades ribeirinhas, indígenas e pesqueiras em relação a qualidade da água e saneamento básico, argumentando que, mesmo que essas comunidades se encontrem em aglomerados urbanos, enfrentam problemas relacionados à oferta de água encanada e tratada, levando-os ao racionamento compulsório ou uso de fontes alternativas das quais não se sabe qual a procedência ou qualidade. Estes autores ainda discorrem sobre as zonas rurais, onde a situação é ainda mais precária, afirmando que o poder público sequer tinha conhecimento das condições de saneamento básico, levando a população à busca de fontes alternativas pela metodologia tradicional (experiência de uso e aparência visual).

Após o rompimento da barragem, instituições públicas e privadas estabeleceram ações e programas de monitoramento da situação na Bacia do Rio Paraopeba, com diferentes enfoques, dados a partir das demandas surgidas após o desastre, muitas delas relacionadas ao abastecimento de água potável. A Agência Nacional de Águas (ANA), o Instituto Mineiro de Gestão das Águas (IGAM), a Companhia de Saneamento de Minas Gerais (COPASA) e Companhia de Pesquisa de Recursos Minerais (CPRM), instituíram uma rede integrada de monitoramento de qualidade das águas e sedimentos.

Sendo assim, para qualificar a discussão sobre o impacto do rompimento da barragem da Vale na organização socioeconômica, será utilizado o Índice de Qualidade das Águas (IQA), empregado para avaliar a qualidade da água visando o seu uso para o abastecimento público após tratamento, e que, no entanto, apresenta limitações, uma vez que não analisa parâmetros importantes para o uso direto da água (ANA, 2020). Logo, para se garantir uma melhor análise, serão abordadas também as concentrações de metais pesados (ferro, cobre, manganês e cromo), oxigênio dissolvido e turbidez, pelas quais indicam a qualidade da água, perante a legislação, para uso no abastecimento público. A discussão da qualidade da água abrangerá o trecho do rio que percorre cinco municípios da Região do Médio Paraopeba, sendo Brumadinho, Mário Campos, São Joaquim de Bicas, Betim e Juatuba, afetados pelo desastre do rompimento da barragem.

Por fim, faz-se importante a reflexão acerca dos resultados das análises de qualidade da água e das ações e estratégias do poder público e pela empresa, a partir do princípio do poluidor pagador, em relação à mitigação e reparo dos impactos ambientais causados no que se refere ao acesso e uso da água.

Com base nesse contexto, o objetivo do presente artigo é discutir os impactos socioambientais surgidos com a deterioração da qualidade da água da Bacia do Rio Paraopeba, após o rompimento da barragem de rejeitos minerários em Brumadinho.

\section{Metodologia}

A pesquisa utiliza os métodos de pesquisa descritivo e exploratório, com a finalidade de discutir a qualidade da água em municípios do Médio Paraopeba. Para isso, parte-se de uma pesquisa bibliográfica a fim de relacionar as principais discussões sobre a temática e contextualizá-las a partir do evento crise do rompimento da barragem da Mina Córrego do Feijão.

A partir de uma pesquisa documental, foi elaborado um mapa de georreferenciamento com auxílio do software QGIS Development Team (2020) (Figura 1) de cinco municípios do Médio Paraopeba (Brumadinho, São Joaquim de Bicas, Mário Campos, Betim e Juatuba), apresentando as classificações censitárias e dos corpos hídricos da região. 

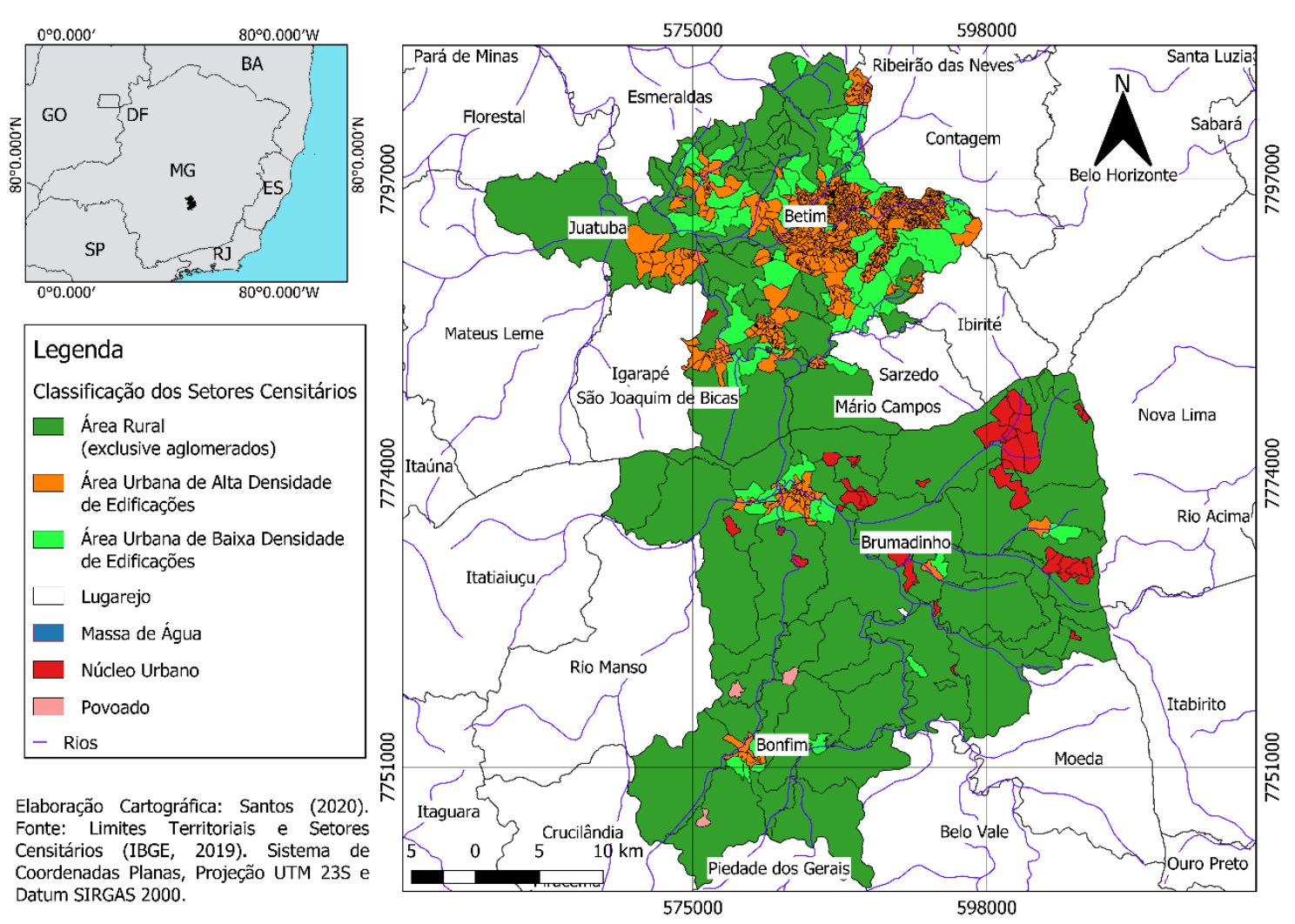

Elaboração Cartográfica: Santos (2020) Fonte: Limites Territoriais e Setores Censitários (IBGE, 2019). Sistema de Coordenadas Planas, Projeção UTM 235 Datum SIRGAS 2000.

Figura 1. Georreferenciamento e classificação de alguns municípios do Médio Paraopeba por setores censitários.

Por meio dos relatórios da SOS Mata Atlântica (2019; 2020), foram extraídos os resultados das análises do índice de qualidade das águas (IQA). A classificação final atribuída aos resultados encaixa-se nos indicadores de qualidade, que variam entre ótimo, bom, razoável, ruim e péssimo (ANA, 2020), como mostrado na Tabela 1.

Tabela 1. Classificação do índice de qualidade da água (IQA).

\begin{tabular}{|c|c|}
\hline Nível de Qualidade & Faixa de Variação do IQA \\
\hline Ótimo & $91-100$ \\
\hline Bom & $71-90$ \\
\hline Razoável & $51-70$ \\
\hline Ruim & $26-50$ \\
\hline Péssimo & $0-25$ \\
\hline
\end{tabular}

Fonte: Agência Nacional das Águas (2020).

No entanto, Cunha (2013) salienta para o fato de que as análises isoladas que compõe o IQA não são o suficiente para uma análise precisa da qualidade da água, uma vez que as oscilações das variáveis compensam umas às outras, mascarando flutuações importantes no ambiente, tendo como solução alternativa, a avaliação dos padrões de lançamento das legislações vigentes em relação à presença de metais pesados. Portanto, 
foram analisadas ainda as concentrações de metais pesados ( $\mathrm{Fe}, \mathrm{Cu}, \mathrm{Mn}$ e $\mathrm{Cr}$ ), oxigênio dissolvido e turbidez a fim de verificar se os valores estão em concordância com o estabelecido na Deliberação COPAM/CERH-MG no 01/2008 (Minas Gerais, 2008). Estes dados obtidos pela SOS Mata Atlântica $(2019$; 2020) podem indicar os impactos e a condição ambiental do Rio Paraopeba após o rompimento da barragem.

\section{Resultados e discussão}

Os Municípios de Brumadinho, Mário Campos, São Joaquim de Bicas, Betim e Juatuba, localizadas na região onde ocorreu o rompimento da barragem de rejeitos minerários no Complexo da Mina Córrego do Feijão, conforme mapa representado na Figura 1, integram a Bacia Hidrográfica do Rio Paraopeba.

Foram classificados os setores censitários destes municípios, que levam em consideração a quantidade de domicílios e a distância entre as habitações, sendo área rural, onde há baixa densidade populacional e grandes extensões de terra rústica, área urbana, de alta densidade de edificações, a área urbana de baixa densidade de edificações, lugarejo, massa de água, núcleo urbano e povoação. Com essa classificação (Figura 1), é possível notar que, em sua maioria, existem maiores concentrações de áreas rurais. Geralmente, são nestas áreas onde se encontram comunidades tradicionais, bem como povos de tradição religiosa e ancestral de matriz africana, além de comunidades ribeirinhas, indígenas e pesqueira, que são respaldadas legalmente no que tange a proteção de seus direitos de apropriação dos territórios (Brasil, 2007). Os territórios das comunidades tradicionais, a partir da dimensão simbólica, é o que permite manter viva a memória do grupo e transpor para o concreto os limites físicos indispensáveis à reprodução social coletiva (Minas Gerais, 2014). Esses territórios, imbuídos de significação a partir dos antepassados, como Costa (2015) reflete, é o que dá o sentido de pertencimento a um grupo, que inscrevem nos territórios novos acontecimentos e significados, mas sempre vivenciados a partir da tradição, que singulariza as formas e usos do ambiente em que vivem e que, por conseguinte, reforçam a indissociabilidade da reprodução social e material aos recursos existentes nos territórios.

Nesse sentido, compreender e analisar a qualidade de um dos recursos mais essenciais à vida, pode indicar como se pode avançar na discussão da proteção dos recursos e da qualidade de vida. Um possível método para auxiliar na discussão da qualidade dos recursos hídricos é o IQA. A partir de então, foram extraídos os valores desse índice para os trechos do rio nos cinco municípios (Tabela 2).

Tabela 2. Índice de qualidade da água (IQA) nos anos de 2019 e 2020.

\begin{tabular}{|l|c|c|}
\hline \multirow{2}{*}{ Municípios do Médio Paraopeba } & \multicolumn{2}{|c|}{ IQA } \\
\cline { 2 - 3 } & $\mathbf{2 0 1 9}$ & $\mathbf{2 0 2 0}$ \\
\hline Brumadinho & 21,63 & 19,09 \\
\hline Mário Campos & 14,00 & 21,63 \\
\hline São Joaquim de Bicas & 18,22 & 19,09 \\
\hline Betim & 19,25 & 20,36 \\
\hline Juatuba & 23,69 & 20,36 \\
\hline
\end{tabular}

Fonte: SOS Mata Atlântica $(2019 ; 2020)$.

Observa-se que nos anos de 2019 e 2020 (Tabela 2), em todas os cinco municípios analisados, o trecho do rio apresentou péssima qualidade, seguindo a classificação pela 
ANA (2020), o que não resultou em melhorias na qualidade da água. Ainda assim, outros aspectos devem ser observados ao analisar a condição da qualidade das águas do Paraopeba. Por sua bacia estar em região historicamente impactada pelo lançamento de esgotos públicos in natura, pela atividade de empreendimentos minerários, agrossilvipastoris, e uma grande porção do território pertencer à Malha Metropolitana de Belo Horizonte, o rio já apresentava um índice de contaminação considerável, e por isso, a sua situação não pode ser atribuída somente ao rompimento da barragem (FIEMG, 2020).

0 Rio Paraopeba enquadra-se como um corpo hídrico de classe 2, e por estar localizado no Estado de Minas Gerais, segue às exigências da Resolução COPAM/CERH-MG no 1/2008 (Minas Gerais, 2008), podendo ser destinado para:
a) o abastecimento para consumo humano, após tratamento convencional;
b) a proteção das comunidades aquáticas;
c) a recreação de contato primário, tais como natação, esqui aquático e mergulho, conforme Resolução CONAMA no 274, de 29 de novembro de 2000;
d) a irrigação de hortaliças, plantas frutíferas e de parques, jardins, campos de esporte e lazer, com os quais o público venha a ter contato direto; e
e) a aquicultura e à atividade de pesca.

Além da caracterização do uso da água do Rio Paraopeba, a Resolução COPAM/CERHMG no 1/2008 (Minas Gerais, 2008) determina as condições e padrões de qualidade das águas e das condições de qualidade dos ambientes aquáticos para a classe 2. Nas Tabelas 3 e 4 encontram-se descritos os resultados das análises físicas e químicas, para os anos de 2019 e 2020, respectivamente, em comparação com o padrão de qualidade da água em Minas Gerais.

Tabela 3. Análises físicas e químicas e padrões de qualidade das águas, para o ano de 2019.

\begin{tabular}{|l|c|c|c|c|c|c|}
\hline Municípios do Médio Paraopeba & $\begin{array}{c}\text { OD } \\
\text { (mg/L) }\end{array}$ & $\begin{array}{c}\text { Turbidez } \\
\text { (NTU) }\end{array}$ & $\begin{array}{c}\text { Ferro } \\
\text { (mg/L) }\end{array}$ & $\begin{array}{c}\text { Cobre } \\
\text { (mg/L) }\end{array}$ & $\begin{array}{c}\text { Manganês } \\
\text { (mg/L) }\end{array}$ & $\begin{array}{c}\text { Cromo } \\
\text { (mg/L) }\end{array}$ \\
\hline Brumadinho & 3,20 & 104 & 6,5 & 3,3 & 2,8 & 1,2 \\
\hline Mário Campos & 2,53 & 6.890 & 5,0 & 4,5 & 2,2 & 0,9 \\
\hline São Joaquim de Bicas & 1,90 & 6.170 & 7,0 & 2,6 & 1,8 & 0,8 \\
\hline Betim & 5,48 & 1.052 & nd & nd & nd & nd \\
\hline Juatuba & 3,88 & 26,9 & 5,4 & 3,8 & 2,3 & 1,1 \\
\hline Padrão legal (Minas Gerais, 2008) & $\geq 5,0$ & até 100 & 0,3 & 0,009 & 0,1 & 0,05 \\
\hline
\end{tabular}

Fonte: SOS Mata Atlântica (2019). Legenda: OD = Oxigênio dissolvido; nd = Não disponível.

Tabela 4. Análises físicas e químicas e padrões de qualidade das águas, para o ano de 2020.

\begin{tabular}{|l|c|c|c|c|c|c|}
\hline Municípios do Médio Paraopeba & $\begin{array}{c}\text { OD } \\
\text { (mg/L) }\end{array}$ & $\begin{array}{c}\text { Turbidez } \\
\text { (NTU) }\end{array}$ & $\begin{array}{c}\text { Ferro } \\
\text { (mg/L) }\end{array}$ & $\begin{array}{c}\text { Cobre } \\
\text { (mg/L) }\end{array}$ & $\begin{array}{c}\text { Manganês } \\
\text { (mg/L) }\end{array}$ & $\begin{array}{c}\text { Cromo } \\
\text { (mg/L) }\end{array}$ \\
\hline Brumadinho & 5,69 & 215 & 5,90 & 0,53 & 1,80 & 0,85 \\
\hline Mário Campos & 7,15 & 582 & 6,20 & 0,40 & 1,80 & 0,50 \\
\hline São Joaquim de Bicas & 3,63 & 585 & 4,30 & 0,27 & 0,80 & 0,50 \\
\hline Betim & 5,70 & 594 & 3,80 & 0,20 & 1,20 & 0,85 \\
\hline Juatuba & 4,67 & 634 & 5,00 & 0,34 & 2,10 & 0,66 \\
\hline Padrão legal (Minas Gerais, 2008) & $\geq 5,0$ & até 100 & 0,3 & 0,009 & 0,1 & 0,05 \\
\hline
\end{tabular}

Fonte: SOS Mata Atlântica (2020). Legenda: OD = Oxigênio dissolvido. 
No ano de 2019 (Tabela 3), a concentração da turbidez encontra-se dentro dos padrões exigidos pela legislação apenas trecho do Município de Juatuba, onde os outros pontos de monitoramento estavam com a concentração bem superior ao exigido. Cenário este que muda ao decorrer do ano, onde, em 2020 algumas dos parâmetros analisados diminuíram e outras aumentaram (Tabela 4) (SOS Mata Atlântica, 2020), porém, não atendem ao padrão legislativo. Esse fator ocorre em decorrência dos períodos chuvosos e de variações de vazões do rio, proporcionando a lixiviação dos sedimentos para os demais trechos. Apenas os valores para o trecho no Município de Betim (Tabela 3) estão de acordo com a legislação, os demais valores de OD não se enquadram na Resolução COPAM/CERH no 01/2008 (Minas Gerais, 2008). Ressalta-se também que a elevada turbidez acarreta impactos negativos para o ecossistema marinho devido à dificuldade de a luz atravessar a água, associada a outros fatores (excesso de nutrientes em decomposição e altas temperaturas), esta elevação resulta em baixos valores de oxigênio dissolvido (SOS Mata Atlântica, 2019).

A atividade de extração mineral gera uma grande quantidade de resíduos incorporados de metais pesados que são destinados para as barragens de rejeitos minerários. De acordo com o relatório apresentado pela SOS Mata Atlântica (2019), grandes quantidades de metais presentes na água trazem riscos aos organismos vivos, à saúde humana e ao meio ambiente. As concentrações dos metais pesados, como o cobre, cromo, ferro e manganês estão acima da norma legal vigente. De acordo com Nascimento e Barbosa (2005), estes metais são severos poluentes, podendo causar danos aos organismos humanos e ao meio ambiente, podendo associar estruturas orgânicas que podem ser metabolizadas e participar dos processos fisiológicos, gerando toxicidade para diferentes espécies.

O ferro e o manganês são os responsáveis pela tonalidade alaranjada/avermelhada da água por intermédio da oxidação de suas soluções na água em contato com o ar, podendo ocasionar problemas para os seres humanos e animais em relação à sua fisiologia (Menezes Filho, 2009). Já o cobre, pode provocar lesões aos rins, inibir a produção de urina e causar anemia devido à destruição dos glóbulos vermelhos (SOS Mata Atlântica, 2020).

Com a contaminação de metais pesados após o rompimento da barragem da Vale e os possíveis riscos à saúde humana e aos organismos vivos, houve a recomendação de que a água do Rio Paraopeba não fosse utilizada para nenhum de seus múltiplos usos por tempo indeterminado (FEAM, 2020), a Secretaria de Estado de Meio Ambiente e Desenvolvimento Sustentável (SEMAD), a Secretaria de Estado da Saúde (SES) e a Secretaria de Estado de Agricultura, Pecuária e Abastecimento (SEAPA), junto aos órgãos responsáveis que realizam de forma periódica análises para controle e vigilância da qualidade da água, entendem que novas recomendações serão feitas quando os resultados desses monitoramentos forem suficientemente conclusivos.

Em notas técnicas conjuntas publicadas pela Secretaria de Estado de Saúde (SES) e pelo Instituto Mineiro de Gestão das Águas (IGAM) (IGAM/SES, 2019) recomendam-se medidas de suspensão dos usos da água bruta do Rio Paraopeba no trecho que abrange os Municípios de Brumadinho até Pompéu (aproximadamente $250 \mathrm{~km}$ ) e da água dos poços e cisternas coletivas e individuais situados dentro de $100 \mathrm{~m}$ das margens do rio no trecho de Brumadinho até o Município de Três Marias. As recomendações de suspensão dos usos da água, seja humano, animal e agrícola, evidenciam a dimensão do impacto do rompimento da barragem, uma vez que a manutenção das diversas atividades econômicas e dos modos de vida das populações às margens estão comprometidas.

No entanto, medidas para que o abastecimento público não seja ainda mais prejudicado tem sido planejadas. A empresa Vale possui um termo de compromisso assinado com a Companhia de Saneamento de Minas Gerais (COPASA), onde criaram um cronograma para a construção de um novo sistema de captação da água para o Sistema de 
Abastecimento do Rio Paraopeba, tendo como um dos compromissos a reativação de grandes poços no Vetor Norte e a interligação dos sistemas do Rio das Velhas e Paraopeba (Oliveira, 2020). Porém, as obras estão atrasadas, onde, segundo os meios de divulgação de imprensa (PIMENTEL, 2021), os responsáveis das obras da mineradora justificam este atraso ocorre pelo fator da pandemia acarretada pela COVID-19, onde foram previstos inicialmente o comissionamento e os primeiros testes no mês de dezembro de 2020. No entanto, pode-se constatar que até março de 2021, as atividades ainda não foram concluídas.

\section{Conclusão}

Os dados referentes ao índice de qualidade da água, dos metais pesados, oxigênio dissolvido e turbidez encontrados nos trechos da água do Rio Paraopeba que passam pelos Municípios de Brumadinho, Mário Campos, São Joaquim de Bicas, Betim e Juatuba indicam altos riscos de comprometimento dos usos múltiplos deste corpo hídrico. Ressalta-se que a péssima qualidade da água não deve ser atribuída exclusivamente ao rompimento da barragem, uma vez que o rio já apresentava altas concentrações de contaminantes, principalmente devido ao lançamento de esgotos domésticos in natura. No entanto, podese concluir que o rompimento da barragem, e os consequentes impactos ambientais ocorridos nesta região intensificaram a deterioração da qualidade da água, tornando-a imprópria para os diversos usos previstos pela classificação da Resolução COPAM/CERH-MG no 1/2008 (Minas Gerais, 2008).

Destaca-se também, que devem ser implementadas algumas soluções que afastem os riscos de desabastecimento, tendo em vista que o rompimento da barragem impactou as atividades de abastecimento público do Sistema Paraopeba operado pela Companhia de Saneamento de Minas Gerais (COPASA), empresa responsável pelo fornecimento de água na maioria das regiões do Estado de Minas Gerais. A deterioração da qualidade da água no Rio Paraopeba após o rompimento da barragem na Mina Córrego do Feijão promoveu modificações nos meios biótico e socioeconômico, acarretando em uma série de restrições imediatas como a redução da captação da água para o abastecimento público e redução de atividades de lazer, recreação e pesca, principalmente devido às concentrações de metais pesados encontrarem-se acima dos padrões legais.

Por fim, torna-se emergente a discussão sobre a gestão das águas, que tem revelado lacunas na elaboração e efetivação de políticas públicas e instrumentos eficazes de gestão ambiental para assegurar ações preventivas, e, que alcancem de forma transparente e participativa a sociedade civil. São discussões de gestão e governança de territórios a nível local e global que precisam ser estabelecidas no cotidiano das relações institucionais, empresariais e comunitárias a fim de garantir que os recursos naturais atendam às necessidades humanas e econômicas, que conservem os ecossistemas e preservem e promovam a diversidade de manifestações socioculturais.

\section{Conflito de interesses}

Os autores declaram não haver conflito de interesses.

\section{Referências}

ANA - Agência Nacional das Águas. Portal da qualidade das águas. 2020. Disponível em: <http://pnqa.ana.gov.br/indicadores-indice-aguas.aspx>. Acesso em: 07 nov. 2020. 
Brasil. Decreto no 6.040, de 7 de fevereiro de 2007. Institui a Política Nacional de Desenvolvimento Sustentável dos Povos e Comunidades Tradicionais. Disponível em: <http://www.planalto.gov.br/ccivil_03/_ato2007-2010/2007/decreto/d6040.htm>. Acesso em: 13 dez. 2020.

Costa, J. B. A. C. A invenção de sujeitos de direito e processos sociais: povos e comunidades tradicionais no Brasil e no Norte de Minas Gerais. Belo Horizonte: Initia-Via, 2015.

CPRM - Companhia de Pesquisa de Recursos Minerais. Monitoramento especial da Bacia do Rio Paraopeba. Belo Horizonte: CPRM, 2019. (Relatório IV - Monitoramento hidrológico e sedimentométrico). Disponível em: <http://www.cprm.gov.br/sace/conteudo/ paraopeba/RT_04_2019_PARAOPEBA.pdf>. Acesso em: 21 nov. 2020.

Cunha, R. W.; Garcia Jr., M. D. N.; Albertoni, E. F.; Palma-Silva, C. Qualidade de água de uma lagoa rasa em meio rural no sul do Brasil. Revista Brasileira de Engenharia Agrícola e Ambiental, $\quad$ v. 17, $\quad$ n. 7, p. 770-779, 2013. https://doi.org/10.1590/s141543662013000700012

FEAM - Fundação Estadual do Meio Ambiente. Recomendação quanto ao uso da água do Rio Paraopeba. Disponível em: <http://www.feam.br/component/content/article/15/ 1990-recomendacao-quanto-ao-uso-da-agua-do-rio-paraopeba>. Acesso em: 12 nov. 2020.

Felippe, M. F. (Coord.). Minas de Lama: relatório da expedição geográfica no Vale do Rio Paraopeba. Juiz de Fora: Universidade Federal de Juiz de Fora, 2020. Disponível em: <https://www.ufjf.br/poemas/files/2019/04/Terra-2020-Minas-de-lama-Relatorio-deCampo.pdf>. Acesso em: 18 nov. 2020.

FIEMG - Federação das Indústrias do Estado de Minas Gerais. Qualidade da água do Rio Paraopeba. Belo Horizonte: FIEMG, 2020. Disponível em: <https://www7.fiemg.com.br/ publicacoes-internas/artigoqualidadeagua>. Acesso em: 12 nov. 2020.

IGAM - Instituto Mineiro de Gestão das Águas. Boletim Informativo do Cidadão n. 9. Belo Horizonte: IGAM, 2020. Disponível em: <http://www.repositorioigam.meioambiente. mg.gov.br/handle/123456789/3235>. Acesso em: 21 nov. 2020.

IGAM - Instituto Mineiro de Gestão das Águas; SES - Secretaria de Saúde do Estado de Minas Gerais. Nota Técnica no 24/IGAM/GEMOQ/2019: Análise da qualidade das águas do Rio Paraopeba após desastre na Barragem B1. 2019. Disponível em: $<$ https://www.saude.mg.gov.br/images/noticias_e_eventos/000_2019/set_out_nov_deze/ nota\%20tecnica\%20Brumadinho.pdf>. Acesso em: 29 mar. 2021.

Menezes Filho, J. A. Níveis elevados de manganês e déficit cognitivo em crianças residentes nas proximidades de uma metalúrgica ferro-manganês na Região Metropolitana de Salvador, Bahia. Rio de Janeiro: Fundação Oswaldo Cruz, 2009. (Tese de doutorado).

Minas Gerais. Direitos dos povos e comunidades tradicionais. Belo Horizonte: Ministério Público de Minas Gerais, 2014. Disponível em: <http://conflitosambientaismg. lcc.ufmg.br/wp-content/uploads/2014/04/Cartilha-Povos-tradicionais.pdf >. Acesso em: 29 mar. 2021. 
Minas Gerais. Resolução COPAM/CERH-MG no 1, de 05 de maio de 2008. Disponível em: <http://www.siam.mg.gov.br/sla/download.pdf?idNorma=8151>. Acesso em: 12 nov. 2020.

Nascimento, S. A. M.; Barbosa, J. S. F. Qualidade da água do aquífero freático no Alto Cristalino de Salvador, Bacia do Rio Lucaia, Salvador, Bahia. Revista Brasileira de Geociências, v. 35, n. 4, p. 543-550, 2005.

Oliveira, N. Obras de captação do Rio Paraopeba feitas pela Vale não ficam prontas no prazo. Jornal O Tempo, 2020. Disponível em: <https://www.otempo.com.br/cidades/ obras-de-captacao-do-rio-paraopeba-feitas-pela-vale-nao-ficam-prontas-no-prazo1.2394220>. Acesso em: 21 nov. 2020.

Queiroz, T. M.; Oliveira, L. C. P. Qualidade da água em comunidades quilombolas do Vão Grande, Município de Barra do Bugres (MT). Engenharia Sanitária e Ambiental, v. 23, n. 1, p. 173-180, 2018. https://doi.org/10.1590/s1413-41522018166375

SOS Mata Atlântica. Observando os rios: o retrato da qualidade da água na Bacia do Rio Paraopeba após o rompimento da barragem Córrego do Feijão - Minas Gerais. São Paulo, 2019. Disponível em: <https://www.sosma.org.br/wp-content/uploads/2019/02/ SOSMA_Expedicao-Paraopeba_Relatorio.pdf>. Acesso em: 05 nov. 2020.

SOS Mata Atlântica. Observando os rios: o retrato da qualidade da água na Bacia do Rio Paraopeba após o rompimento da Barragem Córrego do Feijão - Minas Gerais. São Paulo, 2020. Disponível em: <https://www.sosma.org.br/wp-content/uploads/2020/01/ observando-rios-brumadinho-2020digital.pdf>. Acesso em: 05 nov. 2020.

Informação da Licença: Este é um artigo Open Access distribuído sob os termos da Licença Creative Commons Attribution, que permite uso irrestrito, distribuição e reprodução em qualquer meio, desde que a obra original seja devidamente citada. 